\title{
Teaching Experience in Courses of Soil and Fertilizer Science for Horticultural Science Major
}

\author{
Yifei Liu ${ }^{1, a}$, Xiaori Han ${ }^{1, b, *}$, Yan Wang ${ }^{1, b}$, Jinfeng Yang ${ }^{1, b}$, Qiaobo Song ${ }^{1, b}$, \\ Qingwen Shi ${ }^{1, b}$ and Hongfei Ren ${ }^{1, b}$ \\ ${ }^{1}$ Shenyang Agricultural University, Shenyang, 110161, China \\ aliuyifeiscience@163.com, bfeifan61@gmail.com \\ ${ }^{*}$ Corresponding author
}

Keywords: Soil and Fertilizer Science; Reform; Experience; Teaching; Horticulture.

\begin{abstract}
Teaching contents, teaching methods and means, teaching characteristics, among others are discussed hereby for soil fertilizer science courses of horticulture in Shenyang Agriculture University. Summary and experience are available for soil fertilizer science course in terms of developing students' interest and enthusiasm in their study, integrated teaching between traditional board-writing and multimedia as well as improving students' practices by means of experimental course teaching. All will serve enhancing teaching quality effectively and provide teaching practical experience for better cultivation of scientific and technical talents in agriculture, who are expected to be innovative in soil fertilizer science field.
\end{abstract}

\section{Introduction}

As the saying goes that food is the first necessity and food comes from soil, all grows up from the soil, so crops have to rely on fertilizer, for they are plants. What all this has told us that soil and fertilizer (soil and fertilizer resource) are the vital resource for agriculture production and human existence. The soil and fertilizer are the food for crops. Soil Fertilizer Science is a critically basic course in agriculture majors ${ }^{[1-2]}$. Soil is the most important natural resource for a nation, and fertilizer is one of the primary production materials in agriculture industry, while soil fertilizer is closely related with ecotype. Therefore, soil fertilizer science is a significant discipline, as well as one of an essential course for agriculture study, no matter for agriculture production concerns or for ecotope protection concerns. Meanwhile, it is also a professional basic course most essential to many botanic majors in agricultural universities and colleges, as well as a guidance course, compulsory to be finished before each professional course is studied ${ }^{[3]}$. The talent cultivation concept of Shenyang Agricultural University is of good foundation, broad specification, wide adaptability and powerful ability. For this purpose, both courses as soil science and plant nutrient \& fertilizer science are gradually combined into one course as soil fertilizer science for some majors except agriculture resource and environment major. The soil fertilizer science course in Shenyang Agricultural University mostly relies on the National Engineering Laboratory for Efficient Use of Soil Fertilizer Resource in Shenyang Agricultural University, academic innovation team of plant nutrition and new fertilizer, university-level teaching team of plant nutriology, and soil science teaching \& research 
office. Soil fertilizer science is a professional basic course in Shenyang Agricultural University for several majors as agronomy, horticulture, plant protection and forestry. The teaching effectiveness and teaching level for soil fertilizer science will exert a great influence on the integrative competence and professional quality cultivation for college students. Therefore, the writers offer their opinions on how to teach such as a basic course as soil fertilizer science to college students in horticulture, when combing their teaching experience and accumulated ideas in soil fertilizer science over the recent years.

\section{To Cultivate Students' Interest and Enthusiasm in Study}

Interest is to be located, enthusiasm and all potentials inspired to the utmost if people act upon their inner world, so that arduous study may be a pleasure. The ideas to cultivate and inspire students' interest in study, making them full of commitment to learning in initiative manners and explore knowledge actively are of significant influence on teaching effectiveness ${ }^{[4]}$.

In that case, how could ideal instruction results be achieved? Based on our teaching experience over the years, efforts shall be made in the following aspects: $\quad$ (1) To make the students be aware of the importance of such a course to horticulture. First, specific interpretations for all shall be available at the first class when introduction is in lecture, for each major field in horticulture is inseparable to soil fertilizer science, which is the key theoretical knowledge and prerequisite foundation for production practice and scientific research for these students in the future. In addition, they shall bear it in their minds that the academic performance in soil fertilizer science is directly related to their employment opportunities and their work in practice. Just imagine that if a student is not proficient of soil fertilizer science knowledge, he shall be greatly limited in horticulture or other associated agricultural fields presumably, no matter whether he is engaged in sales, research and development, or in management. (2) To teach a lesson well is similar to the situation where the director is for good guidance and actors and actresses are for good acting, so a basic target for teaching design is to make students to learn efficiently. For this, we take students' demands and characteristics into full considerations in teaching design. It is known that learning by students is the base and starting point for teaching by the teachers, for teaching by the teachers proves to be much effective by means of active and initiative learning by students. As a result, teachers are supposed to prepare their lessons carefully before lecturing and elaborately design the teaching progress and methods for each chapter. Besides that, they are supposed to be concentrate on the psychological characteristics and laws of cognition of students in horticulture major, so that teachers are able to inspire students again in a step-by-step way. For instance, during a lecture teachers shall pause for a while on purpose in case of difficult points to make students focus their attention for further thinking. Order of priority and modulation in tone shall stressed to please listeners. In case of key and difficult points, teachers shall emphasize or repeat firmly to attract students' attention. Cases closely related shall be added accordingly both in course preparation and teaching with the combination of intrinsic horticulture features, so as to enhance students' awareness of knowledge points. Meanwhile, a vast number of achievements of some great scientist in horticultural crop nutrition and fertilization shall be offered to let students know about the trade and be concerned about it, for these outstanding scholars are objectives of struggle and models for learning. For example, Professor Su Huairui from Shandong Agricultural University is an academician of Chinese Academy of Engineering. His soil fertilizer philosophy in terms of carbon and nitrogen nutrient theory for fruit trees, nitrogen application in line with carbon presence, stimulating nitrogen with 
carbon, conserving roots for stronger trees for best quality and good harvest, along with his technology of dibble-reserved fertilizer with plastic film mulched in hill orchards. Focus in lecturing for students in different majors shall be different to some extent, so teachers shall have to explain soil fertilizer knowledge specifically to students in each major. For instance, focus for horticulture students shall be on how to improve horticulture product quality and yield by fertilization, on fertility betterment for soil, and on hazards of soil pollution to horticulture products. Above all, integration with practice is highly suggested. During lecturing, nutrient and fertilization technique shall be outlined for these important horticulture products (such as tomatoes, cucumbers, chilies, eggplants, muskmelons, watermelons, apples and lilies, among others) to expand students' scope of knowledge, which is of great advantage to their future work.

\section{Integrated Teaching between Traditional Board-writing and Multimedia}

Teaching media, especially the application of modern teaching media, accelerates easy and efficient transformation in teaching, providing active basis for teaching quality improvement. Multimedia teaching allows multimedia technology to be used in education and teaching for vivid results with some situations where sound, light, shapes and movements are collaborating to act on students' visual and auditory organs. However, traditional board-writing is still irreplaceable, for board-writing in teaching is capable of highlighting key points in a better way, much helpful to cognition and understanding of basic theory knowledge for college students. Meanwhile organized board-writing by teachers will facilitate taking notes for students to understand knowledge system and trains of thought in textbooks ${ }^{[5-7]}$. Nevertheless traditional lecturing with board-writing from the beginning to the end turns out to be dull and abstract, not satisfying for its teaching effects. Thus we change the traditional teaching model and take integrated teaching between traditional board-writing and multimedia for better results. In respect of teaching contents, we integrate and simplify teaching materials in Introduction to Soil Fertilizer Science by Shen Qirong, Fertilizer Science by Han Xiaori and Soil Fertilizer Science by Wu Lishu. In addition, we add a great number of cases in horticulture plant nutrition and efficient fertilization, introduction of cultivation patterns, along with pictures of soilless culture with nutrient solution for horticulture plants. All of these aforesaid shall stimulate students' love and interest in their majors and soil fertilizer science with remarkable effects, so inattention in class is not sensed on the whole.

\section{To improve Students' Practices by Experiment Course}

Experiments in soil fertilizer science selected by our team are strongly linked with horticulture major ${ }^{[8]}$. Moreover, all the students in soil fertilizer science experiment course shall have to carefully collect samples, prepare samples, pre-treat samples and finish analysis and experiments of those

samples in their own group. Some of the experiments may be finished in various ways, and a self-designed experiment is also required. This sort of teaching practice will be beneficial to the innovation training for those students. Prior to each experiment lesson, they are supposed to preview experiment instruction and understand experiment purposes, operation steps, method, principle and attentions. They are supposed to finish experiments independently with standard operation and correct results during each process. They are also supposed to observe and make records carefully. Upon the experiments are over, they are supposed to complete reports for their teachers to summarize accordingly, to demonstrate by operation and explain on the problems in experiments and 
experiment reports. All will prove to be helpful to the cultivation and consolidation of experiment operation skills. The details in our experiment courses include conducting field investigation for different types of soil, digging up a section, measuring soil fertility, identifying fertilizer processing equipment, and identifying true or counterfeit fertilizer and the similar. At the same time, in light of horticulture major, we make use of many pictures of horticulture plants, as collected in practice to let students identify soil nutrient maladjustment syndromes for those important plants with the guidance from their teachers. We also organize them to visit the fieldwork base for teaching and production in Shenyang Agriculture University to know fertilization features and major nutrient deficiency syndromes of horticulture plants ${ }^{[9-10]}$. To sum up, though there are certain teaching methods, there are still no specified ones, and what is the most valuable is to teach in a proper way. Teaching experience concerning soil fertilizer science is to be summed up constantly, aiming at different target audience. Teaching reform measures shall be taken as suitable to the real situation are deemed as a good way to cultivate innovative talents in agriculture field. Working with our counterparts, our teaching team will exert further efforts and advance with times for extensive communication and mutual improvement to contribute ourselves to cultivation of more senior talents in soil fertilizer according to the requirements in Guidelines of the National Program for Medium- and Long-Term Educational Reform and Development.

\section{Acknowledgment}

This research was financially supported by the Teaching Reform Project of Shenyang Agricultural University (Grant No. 2014-117), National Natural Science Foundation of China (Grant No. 31301842), China Postdoctoral Science Foundation (Grant No. 2012M510839 and 2014T70262), the Doctoral Scientific Fund Project of the Ministry of Education of China (Grant No. 20122103120011), Cultivation Plan for Youth Agricultural Science and Technology Innovative Talents of Liaoning Province (Grant No. 2014043), National Natural Science Initial Foundation of Shenyang Agricultural University (Grant No. 20112013), Postdoctoral Science Foundation of Shenyang Agricultural University (Grant No. 105110), Tianzhu mountain talents support program of SYAU and Peanut Nutrition and Fertilizer Program for China Agriculture Research System (Grant No. CARS-14).

\section{References}

[1] LIU Xiu-zhen, On reforming the teaching "Soil fertilizer science" course, Journal of Shanxi Agricultural University(Society Science Edition), vol.3, pp. 183-184, 2004.

[2] LIU Yi-fei, HAN Xiao-ri, The teaching reflection of soil and fertilizer science course for horticultural undergraduate, China Science and Technology Information, vol.17, pp. 146-147, 2012.

[3] QIAN Yuan-huai, ZHANG Jing, and ZENG Qing-tao, Exploration on the reform of the genetics experimental teaching, Laboratory Research and Exploration, vol.3, pp. 18-19, 1998.

[4] LIU Yi-fei, QI Hong-yan, BAI Chun-ming, QI Ming-fang, XU Chuan-qiang, HAO Jing-hong, LI Yan, LI Tian-lai. Grafting helps improve photosynthesis and carbohydrate metabolism in leaves of muskmelon. International Journal of Biological Sciences, vol.7, pp. 1161-1170, 2011. 
[5] ZHANG De-qing, ZHOU Cheng, YANG Qiu-bo, The comprehensive reform of experimental teaching and strengthen the training of innovation abilit, Heilongjiang Researches on Higher Education,vol.10, pp. 164-165, 2005.

[6] ZHOU Guang-li, MA Hai-quan, The fusion of science and education: reform and innovation of higher education concept, China Higher Education Research, vol.8, pp. 15-23, 2012.

[7] HAN Yan-lun, The humanistic orientation of college curriculum reform in foreign countries and in our university curriculum reform enlightenment, University Education Science, vol.2, pp. 83-86, 2005.

[8] Clark B R. The modern integration of research activities with learning and teaching [ J ] . Journal of Higher Education, 1997, 68(03): 242.

[9] YANG Wen-qiang, MA Yun-kuo, LI Wei, The fusion of science and education: the university personnel training strategy choice, Chinese University Science \& Technology, vol.8, pp. 49-51, 2013.

[10]XIA Fan, YU Zhi-he, The reform of microbiology experimental teaching to cultivate students' innovation ability, Microbiology, vol.5, pp. 1023-1026, 2007. 